\title{
An Update Report on the Biosafety and Potential Toxicity of Fullerene-Based Nanomaterials toward Aquatic Animals
}

\author{
Nemi Malhotra $\mathbb{D}^{\mathrm{D}},{ }^{1}$ Gilbert Audira $\mathbb{D}^{\mathrm{D}},{ }^{2,3}$ Agnes L. Castillo $\mathbb{D},{ }^{4}$ Petrus Siregar $\mathbb{D}^{2,3}$ \\ Johnsy Margotte S. Ruallo, ${ }^{5}$ Marri Jmelou Roldan $(1),{ }^{6}$ Jung-Ren Chen $(1), 7$ \\ Jiann-Shing Lee $\oplus^{8},{ }^{8}$ Tzong-Rong Ger $₫{ }^{1,9}$ and Chung-Der Hsiao $\oplus^{2,3,9,10}$ \\ ${ }^{1}$ Department of Biomedical Engineering, Chung Yuan Christian University, Chung-Li 320314, Taiwan \\ ${ }^{2}$ Department of Chemistry, Chung Yuan Christian University, Chung-Li 320314, Taiwan \\ ${ }^{3}$ Department of Bioscience Technology, Chung Yuan Christian University, Chung-Li 320314, Taiwan \\ ${ }^{4}$ Faculty of Pharmacy, The Graduate School and Research Center for the Natural and Applied Sciences, University of Santo Tomas, \\ Manila 1008, Philippines \\ ${ }^{5}$ The Graduate School, University of Santo Tomas, Manila 1015, Philippines \\ ${ }^{6}$ Faculty of Pharmacy and Graduate School, University of Santo Tomas, Manila 1008, Philippines \\ ${ }^{7}$ Department of Biological Science \& Technology, College of Medicine, I-Shou University, Kaohsiung 82445, Taiwan \\ ${ }^{8}$ Department of Applied Physics, National Pingtung University, Pingtung 900391, Taiwan \\ ${ }^{9}$ Center for Nanotechnology, Chung Yuan Christian University, Chung-Li 320314, Taiwan \\ ${ }^{10}$ Research Center for Aquatic Toxicology and Pharmacology, Chung Yuan Christian University, Chung-Li 320314, Taiwan
}

Correspondence should be addressed to Jiann-Shing Lee; jslee@mail.nptu.edu.tw, Tzong-Rong Ger; sunbow@cycu.edu.tw, and Chung-Der Hsiao; cdhsiao@cycu.edu.tw

Received 30 May 2021; Accepted 26 June 2021; Published 19 July 2021

Academic Editor: Dragica Selakovic

Copyright (๑) 2021 Nemi Malhotra et al. This is an open access article distributed under the Creative Commons Attribution License, which permits unrestricted use, distribution, and reproduction in any medium, provided the original work is properly cited.

Fullerene molecules are composed of carbon in the form of a hollow sphere, tube, or ellipsoid. Since their discovery in 1985, they have gained a lot of attention in many science fields. The unique carbon cage structure of fullerene provides immense scope for derivatization, rendering potential for various industrial applications. Thus, the prospective applications of fullerenes have led to assorted fullerene derivatives. In addition, their unique chemical structure also eases them to be synthesized through various kinds of conjugating techniques, where fullerene can be located either on the backbone or the branch chain. In this review, we have compiled the toxicity and biosafety aspects of fullerene in aquatic organisms since the frequent use of fullerene is likely to come in contact and interact with the aquatic environment and aquatic organisms. According to the current understanding, waterborne exposure to fullerene-based nanomaterials indeed triggers toxicities at cellular, organic, molecular, and neurobehavioral levels.

\section{Introduction and Application of Fullerene}

1.1. Introduction of Fullerene. Carbon is known to be found in two allotropes, namely, diamond and graphite. In 1985, Kroto, Curl, and Smalley discovered another allotropic form of carbon, which was fullerene. Because of the discovery and their pioneering efforts, they received the Nobel Prize in 1996 [1]. Fullerenes are regarded as three-dimensional analogs of benzene and composed of carbon atoms that are joined by single and double bonds. Together with fused rings of five to seven carbon atoms, these bonds form a closed or partially closed mesh. Carbon atoms in a fullerene molecule can be found in a variety of sizes and shapes, including hollow spheres, ellipsoids, and tubes [2,3]. The discovered fullerenes consist of various $n$ numbers of carbon atoms, which obeyed a specific rule.

$\mathrm{C}_{60}$, one of the most well-known and abundant forms of fullerenes, is composed of $n=60$ carbon atoms, which are arranged in a spherical cage structure of about $7 \AA$ in diameter. 


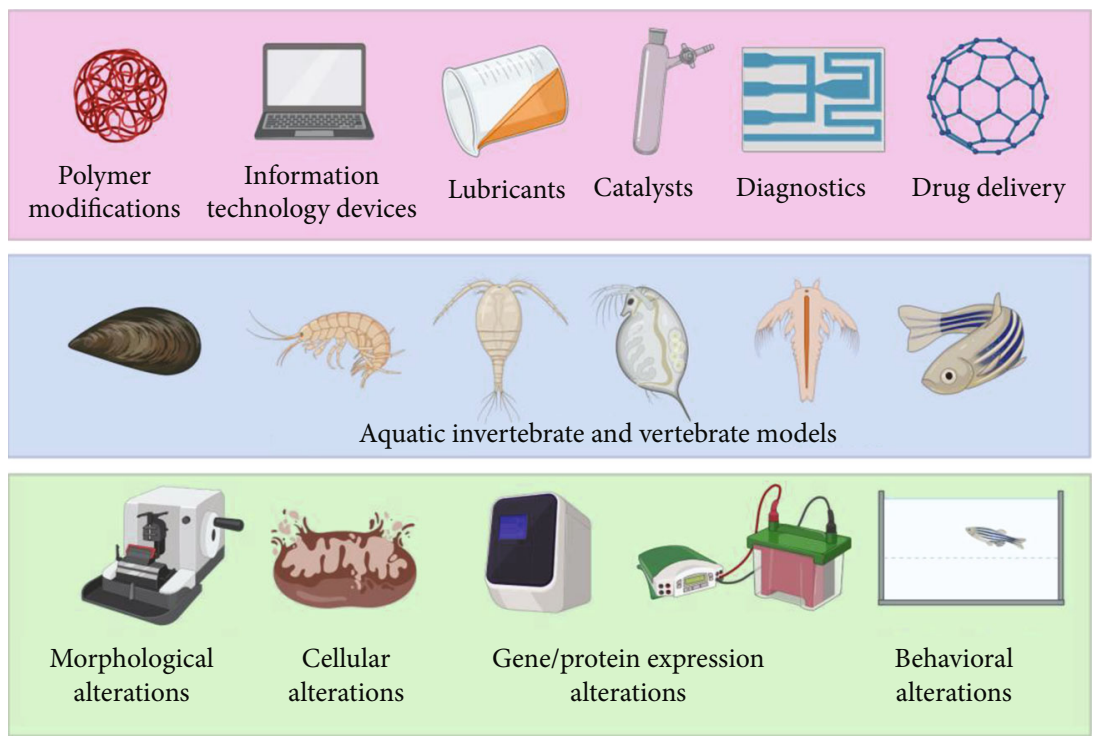

FIgURe 1: Summary of applications, animal models, and methods of fullerene toxicity assessment in aquatic species. The industrial and biomedical applications of fullerene were compiled in the upper panel (pink color). The invertebrate and vertebrate animal models used to perform fullerene toxicity assessment were compiled in the middle panel (blue color). The various methods used to detect fullereneinduced changes at either morphological, cellular, gene/protein expressional, or behavioral levels were summarized in the bottom panel (green color).

Furthermore, to honor the inventor of geodesic domes in the 1960 s, it also goes by the name of buckminsterfullerene [2]. Informally, $\mathrm{C}_{60}$ fullerenes are also known as buckyballs since their shape resembles a soccer ball shape. In $\mathrm{C}_{60}$ fullerenes, there are two types of $\mathrm{C}-\mathrm{C}$ bonds with distinct lengths: $\mathrm{C}_{5}-\mathrm{C}_{5}$ single bonds in the pentagons and $\mathrm{C}_{5}-\mathrm{C}_{6}$ double bonds in the hexagons with $1.45 \AA$ and $1.40 \AA$ in distance, respectively [4]. The $\mathrm{C}_{60}$ has a low specific gravity relative to the diamond (1.65 compared to 3.51). Chemically, the molecule is very stable owing to the fact that destruction of the cages requires temperatures above $1000^{\circ} \mathrm{C}[4,5]$. In addition, besides $\mathrm{C}_{60}$, other fullerenes can consist of numerous carbon atoms, ranging from 30 to 980 , creating various structures with different characteristics and applications.

1.2. Applications of Fullerene. These new forms of carbon's distinctive physical and chemical properties have taken numerous scientists to propose several technological applications. Nowadays, $\mathrm{C}_{60}$ molecules have attracted a lot of attention since they have a high electron affinity and antioxidant and radical scavenging properties, which can absorb many free radicals responsible for aging the skins and grafting surfactants or hydrophilic polymers in aqueous environments [6-8]. Fullerenes can be integrated into shafts and frames for strengthening composite materials with very thin-walled, lightweight, robust carbon structures that make them currently be applied in cosmetic products and sporting goods industries [9]. Recently, several investigations suggested that a lot of the proposed fullerenes are applicable in many areas, including information technology devices, lubricants, catalysts, diagnostics, pharmaceuticals, polymer modifications, energy applications, and environmental fields [2, 3, 6, 10]. Furthermore, the unique cage structure of fullerenes, coupled with their immense scope for derivatization, opens up the potential of fullerenes to be a therapeutic agent. In addition, it has also been extensively used in many biomedical applications, including MRI contrast agents, X-ray imaging contrast agents, anti-HIV drugs, targeted drug delivery systems, and photodynamic therapy [11-13]. Therefore, the production and usage of fullerenes are expected to escalate in the future. However, most fullerenes are nonbiodegradable molecules whose potential toxicity has not been thoroughly investigated so far. The increased demand for fullerenes and their mass production have raised biosafety and environmental concerns. In vivo toxicity testing provides intact systems for the prediction of biological responses. Aquatic invertebrates and vertebrates provide cost, labor, and time-effective platforms for these studies. These in vivo study models provide results on many cellular, anatomical, and physiological characteristics. Moreover, their small size, speedy development, and short life cycle make them attractive for evaluating nanomaterial's toxicological effects. Various methods of toxicity assessments have been developed at different levels of these in vivo model systems, such as morphological alterations assessed under a microscope, cellular alterations, gene/protein expression alteration, biochemical analysis, and behavior alterations. The applications of fullerene, aquatic invertebrate, and vertebrate model systems used to assess the toxicity and methods of toxicity analysis of fullerene are compiled in Figure 1.

\section{Types and Chemical Composition of Fullerene}

2.1. Types of Fullerenes. Fullerenes occur in nature and have a similar structure to graphite, except that they may contain pentagonal rings [14]. Small quantities of fullerene in the form of $\mathrm{C}_{60}, \mathrm{C}_{70}, \mathrm{C}_{76}$, and $\mathrm{C}_{84}$ might be found hidden in 
carbon soot [15]. In 2010, by using Spitzer infrared telescope, NASA also found $\mathrm{C}_{60}$ and $\mathrm{C}_{70}$ in a cloud of cosmic dust surrounding a star [16]. Generally, the synthesis of these fullerenes starts by forming fullerene-rich soot. The original process generates an electric arc between two graphite rods in an inert atmosphere resulting in a vaporized carbon that is subsequently cooled into sooty residue $[1,17]$. In addition, laser ablation of graphite targets or laser pyrolysis of aromatic hydrocarbons can also form carbon soot [17]. By contrast, combustion is the most effective method to produce commercial fullerenes in high-temperature, low-pressure premixed flat flames [18]. Later, through these chemical processes, a solid mixture of various fullerenes and other carbons is formed. Afterward, by using suitable organic solvents, small amounts of fullerenes are extracted from the soot and separated by liquid chromatography [17].

The closed buckyballs and cylindrical carbon nanotubes are two major fullerene classes with distinct properties and applications, although some hybrid structures also exist besides these families, including carbon nanobuds. These classes have unique properties due to their carbon atom arrangement. Each carbon atom in the closed fullerenes, especially $\mathrm{C}_{60}$, bonds to three others and is $\mathrm{sp}^{2}$ hybridized. These delocalized electrons on the surface of a threedimensional structure stabilize the spheroid structure of $\mathrm{C}_{60}$ by resonance [19]. Distorted buckyballs with $n=24,28,32$, 36 , and 50 were also obtained, but they are predicted to be unstable. Other relatively common clusters with $n=70,72$, $74,76,80,82$, and 84 exist but are less abundant in the experimentally produced carbon soot [20]. A general rule is observed that the chemical reactivity significantly decreases with the increasing size of the fullerene molecule. The closed buckyballs, in contrast to graphite, are not electrically conductive. Due to their spherical shape, buckyballs are well known as suitable lubricants. Moreover, buckyballs might be useful in medicine deliveries in the future because of their unique and hollow cage. On the other hand, cylindrical fullerenes, another major family of fullerenes, are known as carbon nanotubes or buckytubes. Every nanotube is a single molecule consisting of millions of carbon atoms. Generally, this molecule's width is only a few nanometers; however, the length ranges from less than a micrometer to several millimeters [21]. Most of the time, the nanotubes have closed ends; however, it is also possible to be open-ended. Carbon nanotubes exhibit higher tensile strength, flexibility, elasticity, and high thermal conductivity [22,23]. They are often utilized to reinforce composite materials with improved mechanical, electrical, and thermal properties. In addition, these nanotubes may act electrically as either a metal or a semiconductor depending on the hexagonal units' orientation in the tube wall with the tube axis [24].

2.2. Chemical Composition of Fullerene. Since every fullerene possesses abundant cyclohexanes, they are very aromatic and have stable and inert carbon bonds. The insolubility in aqueous media and poor miscibility of fullerenes limit the biological applications, and its strong tendency to form selfaggregate also leads to phase separation problems $[25,26]$. Since pristine fullerenes and carbon nanotubes lack hydrogen atoms or other groups on their surface, they cannot undergo substitution reactions. Because of this reason, they need to carry out surface modification in order to promote the functionalization on their surface [26]. It is worth noting that fullerenes are the only known allotropic carbons that are soluble in common organic solvents (for example, toluene) despite a limited solubility in most solvents [4, 26-28]. Once fullerenes are dissolved in organic solvents, various chemical reactions tend to proceed in solution, and thus, numerous fullerene derivatives are formed. In producing these derivatives, fullerenes can undergo various chemical reactions, e.g., oxidation, reduction, nucleophilic substitutions, halogenations, hydrogenations, radical additions, transition-metal-complex formations, and regioselective functionalization reactions [2]. By attaching active groups to their surface and modifying their basic properties to be adjusted to specific functions, the increment in fullerenes reactivity has been demonstrated.

Functionalized buckyballs are primarily divided into two classes: endohedral and exohedral fullerenes. Exohedral fullerenes are formed with substituents outside their cages, while endohedral fullerenes are formed with trapped atomes or molecules inside their cages [27]. These endohedral and exohedral derivatives have been shown to exhibit attractive photonic, electronic, superconducting, lubrication, biomedical, and magnetic properties due to their unique structures [25]. Similar studies have shown that the carbon nanotubes require chemical modifications by attaching the functional groups to improve the compatibility, processing, and solubility with host materials in the engineering of multifunctional materials $[29,30]$. Accordingly, the chemical modifications maintain the interesting pristine fullerenes electrochemical, chemical, and physical properties and make them more applicable and reactive for many applications [31].

\section{Interaction of Fullerene with Aquatic Invertebrates in reference to Bioavailability, Toxicity, and Biosafety}

The invertebrates are among the target groups for nanoparticle (NP) ecotoxicity due to their highly developed cellular internalization processes, such as phagocytosis and endocytosis, of nano- and microscale particles that are essential for physiological functions (cellular immunity and intracellular digestion). The biologic, ecologic, and toxicologic characteristics of invertebrates render them a suitable model to detect chemicals and pollutants in typical habitats, primarily via bioaccumulation potential. In addition, invertebrates also offer an advantage to evaluate the individual effect of exposure to the tested chemicals. Assumptions have also been made that the invertebrate model can be used to predict the effects of some toxicants at population and community levels. Thus, they can early indicate the ecosystem function and structure's deterioration or restoration [32]. We are going to discuss the effects of fullerene in aquatic invertebrate organisms in the current section.

First, the chronic toxicity of fullerene $\mathrm{C}_{60}$ was tested on Chironomus riparius, also known as the harlequin fly, and 
hypothesized that higher food concentration could reduce the toxic response. This 10-day test was performed by using Urtica sp. as food in two different concentrations, which were 0.5 and $0.8 \%$. The test was conducted in sediment that contained fullerene with masses of 0.36 to $0.55 \mathrm{mg} / \mathrm{cm}^{2}$. The results demonstrated that at $0.5 \%$ food treatment, a significant difference in growth-related endpoints was found, whereas little effect was observed for the higher food concentrations than the control group. Furthermore, although they found agglomerates of fullerene in the gut, the microvilli were damaged. Taken together, this finding demonstrated the fullerene's potential toxicity to C. riparius in terms of morphological changes and larval growth inhibition [33]. Next, a similar study on the chronic effects of $\mathrm{C}_{60}$ on different life stages of C. riparius in 10-day growth (larvae) and 42-day (adult midges) emergence tests was conducted. The results showed a decrease in body length at a concentration of $0.0025-20 \mathrm{mg} / \mathrm{kg} \mathrm{C}_{60}$, but effects disappeared at higher concentrations. The study stated that small fullerene agglomerates more significantly affected $C$. riparius than the large ones, as shown with high doses of $\mathrm{C}_{60}$. Further, a bellshaped dose-response relationship was observed in the $\mathrm{C}_{60}$ exposure results, which might be caused by the relative growth pattern. This dose-response relationship makes ecological risk assessment of $\mathrm{C}_{60}$ more difficult since several effects occur at low concentrations [34].

Several prior studies had assessed the toxicity of $\mathrm{C}_{60}$ in Mytilus. First, the toxicity of $\mathrm{C}_{60}$ at 1,5 , and $10 \mu \mathrm{g} / \mathrm{ml}$ concentrations was investigated in marine bivalve Mytilus. From the results, the $\mathrm{C}_{60}$ expressed no significant effect in lysosomal membrane stability, which indicated an absence of a major toxicity effect. However, $\mathrm{C}_{60}$ suspension led to the release of lysozyme and extracellular oxyradical and nitric oxide production in a concentration-dependent manner. Therefore, the results supported the speculation about the bivalve immune system as a key target of NPs [35]. Forward, in a similar study with Mytilus sp., a marine mussel, they were exposed for three days to either $0.10-1 \mathrm{mg} / \mathrm{l}$ of $\mathrm{C}_{60}$ and 32$100 \mu \mathrm{g} / \mathrm{l}$ of polycyclic aromatic hydrocarbon (PAH) fluoranthene or the combination of both compounds. The observed results depicted a concentration-dependent increase in DNA strand breaks caused by $\mathrm{C}_{60}$ and fluoranthene individually; however, their combined exposure enhanced the level of DNA strand breaks together with a twofold increment in total glutathione (GSH) content, indicating oxidative stress. The work concluded the generation of toxic response and damage with additive effects. Afterward, the research group suggested further analysis of $\mathrm{C}_{60}$ and fluoranthene alone or in combination for a longer duration to establish concrete toxicity results [36]. Further, Mytilus galloprovincialis Lam. were also exposed to $\mathrm{C}_{60}$ at $0.01,0.1$, and $1 \mathrm{mg} / \mathrm{l}$ concentration for $72 \mathrm{~h}$. Later, the accumulation of $\mathrm{C}_{60}$ in the digestive gland was demonstrated to induce dephosphorylation of mTOR with no oxidative stress for cellular distribution of $\mathrm{C}_{60}$ at $0.01 \mathrm{mg} / \mathrm{l}$ concentration. The study suggested that mussels' most affected functions were related to the organization of the cytoskeleton, energy metabolism, and lysosomal activity $[36,37]$. Lastly, in another report on Mytilus galloprovincialis, the mussels were exposed to $C_{60}(0.01,0.1$, and
$1 \mathrm{mg} / \mathrm{l}), \mathrm{B}[\mathrm{a}] \mathrm{P}(5,50$, and $100 \mu \mathrm{g} / \mathrm{l})$, and $\mathrm{B}[\mathrm{a}] \mathrm{P}(5,50$, and $100 \mu \mathrm{g} / \mathrm{l})$ in combination with $\mathrm{C}_{60}(1 \mathrm{mg} / \mathrm{l})$. Afterward, the uptake of each treatment group was measured by a different set of chromatography techniques. The study supports the hypothesis of an interaction between these two compounds and demonstrated an antagonistic relationship at the genotoxic and proteome expression level. However, as this effect is observed on a single concentration, the research group further suggested that other dosage concentrations should also be investigated $[37,38]$.

Further, ecotoxicities of several fullerenes $\left(\mathrm{C}_{60}, \mathrm{C}_{70}\right.$, and $\mathrm{C}_{60}$-phenyl- $\mathrm{C}_{61}$-butyric acid methyl ester (PCBM)) on Lumbriculus variegatus (California blackworm), a benthic organism, were assessed. The results indicated that 25 to $150 \mathrm{mg} / \mathrm{kg}$ of $\mathrm{C}_{60}$ reduce the population growth of L. variegatus, even though no effect on the organism's growth or weight was observed after treated with $25 \mathrm{mg} / \mathrm{kg}$ of $\mathrm{C}_{70}[38,39]$. Similarly, in another study, 10 and $50 \mathrm{mg} / \mathrm{kg}$ dry mass of $\mathrm{C}_{60}$ were exposed to L. variegatus for 28 days. Later, it was found that the survival rate or reproduction of $L$. variegatus was not affected by $\mathrm{C}_{60}$. However, the impairment of feeding activity observed in the study indicated the $\mathrm{C}_{60}$, s disruptive effect on worm feeding. In addition, electron and light microscopy also detected $\mathrm{C}_{60}$ agglomerates in fecal pellets, and they were not absorbed in gut epithelial cells. This study also reported that through feeding and egestion, fullerene transfer from sediment-to-sediment surface occurred in L. variegatus. This phenomenon might increase the bioavailability of $\mathrm{C}_{60}$ to epibenthic organisms and facilitate the $\mathrm{C}_{60}$ transfer in the food web $[39,40]$.

The acute toxicity of $\mathrm{C}_{60}$ was also assessed on Daphnia magna, Hyalella Azteca, and Copepods. The 21-day exposure of $\mathrm{C}_{60}$ in different concentrations (2.5 and $5 \mathrm{ppm}$ ) generated a significant delay in molting and a reduction in offspring production, producing impacts at a population level [40, 41]. Further toxicity tests were performed in Daphnia magna and Moina macrocopa with $4 \mathrm{~h} / \mathrm{d}$ sunlight exposure, testing the photo-toxicity of fullerene by the environmental level of ultraviolet light. The neonates were exposed acutely to $\mathrm{aqu} / \mathrm{nC}_{60}$ filtered through $0.2 \mu \mathrm{m}(0,0.462,0.925,1.85,3.70$, and $7.40 \mathrm{mg} / \mathrm{l})$ and filtered through $0.45 \mu \mathrm{m}(0,0.703,1.40$, $2.81,5.62$, and $11.2 \mathrm{mg} / \mathrm{l})$ at $21 \pm 1^{\circ} \mathrm{C}$, and observations were recorded at 24, 48, 72, and 96 hours. From the results, antioxidant enzyme activities were observed to be increased by coexposure to $\mathrm{C}_{60}$ aqueous suspensions and sunlight. The results demonstrated that fullerene led to oxidative damage to D. magna, aggravated by natural sunlight [41, 42]. Next, in another study, $\mathrm{C}_{60}$ NPs were prepared at different concentrations by sonication $(0.5,1,2,3,4,5,6,7,8,9$, and $10 \mathrm{ppm})$ and ultrafiltration $(40,180,260,350,440,510,700$, and $880 \mathrm{ppb}$ ) before exposure to Artemia salina for 1, 6, 12, 24, 36,48 , and $96 \mathrm{~h}$ for acute toxicity testing. The results showed that sonicated $\mathrm{C}_{60}$ caused varied mortalities in different chosen stages of this brine shrimp at 15-24 h, 24-48 h, 72-96 h, 6 to 7 days old, and adult. In contrast, filtered solution showed increased mortality with increased $\mathrm{C}_{60} \mathrm{NP}$ concentrations $[42,43]$. Next, a prior study analyzed the antioxidant and oxidative damage responses in the several regions of Lophiotoma acuta (marbled turrid) and a bacterium (feeding on 
mucus produced by L. acuta) after $\mathrm{C}_{60}$ exposure for $24 \mathrm{~h}$. After $1.0 \mathrm{mg}$ of $\mathrm{C}_{60} / 1$ was administered, low levels of antioxidant capacity and lipid peroxidation were displayed in the anterior region of L. acuta, indicating that complex interactions between estuarine organisms and associated bacteria could be compromised by nanomaterials, which is $\mathrm{C}_{60}$ in this case. This finding highlights the importance of proper evaluation of $\mathrm{C}_{60}$ usage, considering the ecological consequences $[43,44]$. Next, $\mathrm{C}_{60}$ was tested in Daphnia magna for $48 \mathrm{~h}$ acute toxicity tests. From the results, $\mathrm{C}_{60}$ increased the mortality rate with an increased concentration of $\mathrm{C}_{60}$ and caused even more severe toxicity effects at lower $\mathrm{C}_{60}$ concentrations $[44,45]$. Similarly, the amount of $\mathrm{C}_{60}$ stored in the body at a particular time due to the exposure of $\mathrm{C}_{60}$ was also evaluated on Daphnia. After being treated with $1 \mathrm{mg} / \mathrm{l}$ of $\mathrm{C}_{60}, \mathrm{C}_{60}$ was taken with a body burden of $413 \mu \mathrm{g} / \mathrm{g}$ wet weight. $\mathrm{C}_{60}$ was observed to be accumulated significantly in the gut of Daphnia. Moreover, gut impairments, reduced digestion and filtration rates, and inhibited several digestive enzymes, such as $\beta$-galactosidase, trypsin, cellulose, and amylase, were shown after the exposure. The research work provides evidence for limitation in energy acquisition and increases in oxidative damage in Daphnia that might be associated with the $\mathrm{C}_{60}$ bioaccumulation, which causes immobility and mortality later $[45,46]$. In another similar study with the same animal model, the toxicity of $\mathrm{C}_{60}$ in artificial freshwater was investigated. After $2 \mathrm{mg} / \mathrm{l}$ of fullerene solution was administered for 24 hours, the wet weight of the organism's wet mass was $4.5 \pm 0.7 \mathrm{~g} / \mathrm{kg}$. However, after depuration for 24 and $48 \mathrm{~h}$ in clean water, $46 \%$ and $74 \%$ of accumulated fullerene, respectively, were eliminated. Also, large aggregates of fullerenes were found in the gut of Daphnids. Taken together, the study suggested that $D$. magna might have contributed to carrying fullerene from one trophic level to another because of their significant uptake of fullerene and relatively slow depuration $[46,47]$. Further, another behavior study in $D$. magna also discovered that chronic exposure of $\mathrm{nC}_{60}$ (21 days) in different concentrations $(0.1$ or $1 \mathrm{mg} / \mathrm{l})$ yielded a reduction in their feeding ability, hopping, and heartbeat frequencies. Later, the transcriptome analysis depicted this phenomenon which is possibly due to alterations in some underlying physiological functions, including protein degradation, reproduction, energy metabolism, and cell structure repair $[37,38]$. Similarly, $\mathrm{C}_{60}$ and PCBM (is a solubilized version of the C60) were not found to be acutely toxic when tested at $5,10,25$, and $50 \mathrm{mg} / \mathrm{l}$ for 21 days, while $\mathrm{C}_{70}$ had significant acute toxic effects. However, $\mathrm{C}_{60}, \mathrm{C}_{70}$, and PCBM depicted heart rate elevation over time $[47,48]$. In addition, another study demonstrated that accumulated $\mathrm{C}_{60}$ in $D$. magna could be transferred to zebrafish through dietary exposure and accumulated mostly in the intestines; however, no magnification was found $[48,49]$.

Taken together, we envisage that when exposed to Daphnia magna, the suspended $\mathrm{C}_{60}$ nanoparticles revealed protection against short-term UV and fluoranthene photoinduced toxicity, although it caused cellular damage. The cellular components, such as microvilli, mitochondria, and basal unfolding, are protected by $\mathrm{C}_{60}$, which evidenced by transmission electron microscopy in organisms after being shortly exposed to UV and fluoranthene photo-toxicity, while longer exposure time ( 21 days) of $\mathrm{C}_{60}$ at low concentration led to significant cellular damage in the alimentary canal of Daphnia magna $[49,50]$. Further, when $\mathrm{C}_{60}$ was analyzed in Perinereis gualpensis (a Polychaete species), there were no oxidative damage, GSH (glutathione), and GCL (glutamate cysteine ligase) observed in all tested concentrations, even though after 2 and 7 days, the antioxidant capacity was found to be elevated in the treated group, suggesting a possibility for fullerene acting as an antioxidant $[50,51]$. The summary of the toxicity of fullerene-based nanomaterial to aquatic invertebrates is described in Table 1.

\section{Interaction of Fullerene with Aquatic Vertebrates in reference to Bioavailability, Toxicity, and Biosafety}

Identification of nanomaterial toxicity is challenging since the potential usage of nanomaterial exposes them to the environment and eventually harms human health. The assessment of cytotoxicity of nanomaterials is important to understand the actual interaction and interpretation in a biological organism. The quality of NPs depends on the dispersion medium used for their suspension, which may add to their cytotoxicity potential. The main concern of fullerene testing is to identify the associated risk factors. In addition, the defined conditions of laboratories play a large part in understanding the toxicology profile. The comprehension of nanomaterial interaction inside the biological body is essential to understand all aspects of cells, organs, and blood systems. The vertebrate system plays a significant part in providing cheap, easy, and time-efficient animal models to assess toxicity rapidly. In a prior study, fullerenes (100-500 ppb of $\mathrm{C}_{60}$ and $\mathrm{C}_{70}$ and $500-5000 \mathrm{ppb}$ of $\left.\mathrm{C}_{60}(\mathrm{OH})_{24}\right)$ were administered 24-96 hours of postfertilization (hpf) zebrafish embryo. The results showed that while $\mathrm{C}_{60}$ alone led to apoptotic and necrotic cell death, both $\mathrm{C}_{60}$ and $\mathrm{C}_{70}$ were demonstrated to cause mortality, malformations, and pericardial edema in the embryos. On the other hand, even though $\mathrm{C}_{60}(\mathrm{OH})_{24}$ exposure increased embryonic cellular death, it did not lead to apoptosis. Therefore, the study suggested less toxicity of $\mathrm{C}_{60}(\mathrm{OH})_{24}$ compared to $\mathrm{C}_{60}$ [52]. Furthermore, in a similar study in the embryonic zebrafish model conducted by Henry et al., the depletion of $\mathrm{C}_{60}$ from exposure medium and embryonic zebrafish uptake was evaluated [53]. Later, it was found that around $90 \%$ of $\mathrm{C}_{60}$ could be recovered from zebrafish embryo extracts. The toxicological assay revealed that sorption to test vials caused the loss. After 6 hours, this absorption already resulted a decrease of exposure solution to less than $50 \%$ of the initial dose. The embryo uptake of $\mathrm{C}_{60}$ increased throughout the $12 \mathrm{~h}$ exposure. The study suggested that it is necessary to measure the time course of the $\mathrm{C}_{60}$ dose to determine the range of concentrations to which the organism will be exposed. Furthermore, in a prior experiment done by $\mathrm{Zhu}$ et al., the Danio rerio embryo was exposed to $\mathrm{nC}_{60}$ to analyze the developmental toxicity in a $96 \mathrm{~h}$ exposure [54]. The results demonstrated that $1.5 \mathrm{mg} / \mathrm{l}$ of $\mathrm{nC}_{60}$ delayed the development of the zebrafish embryo 


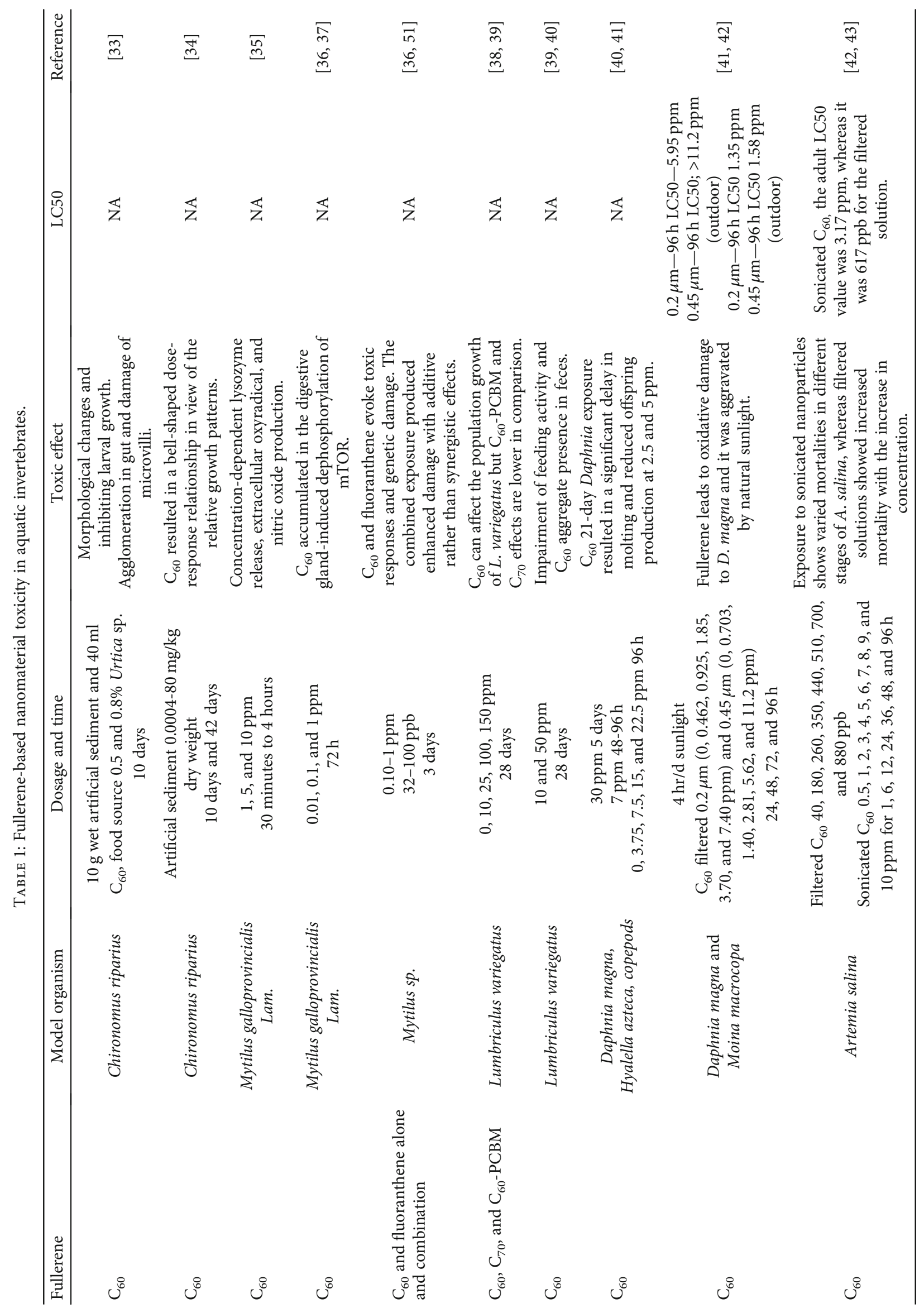




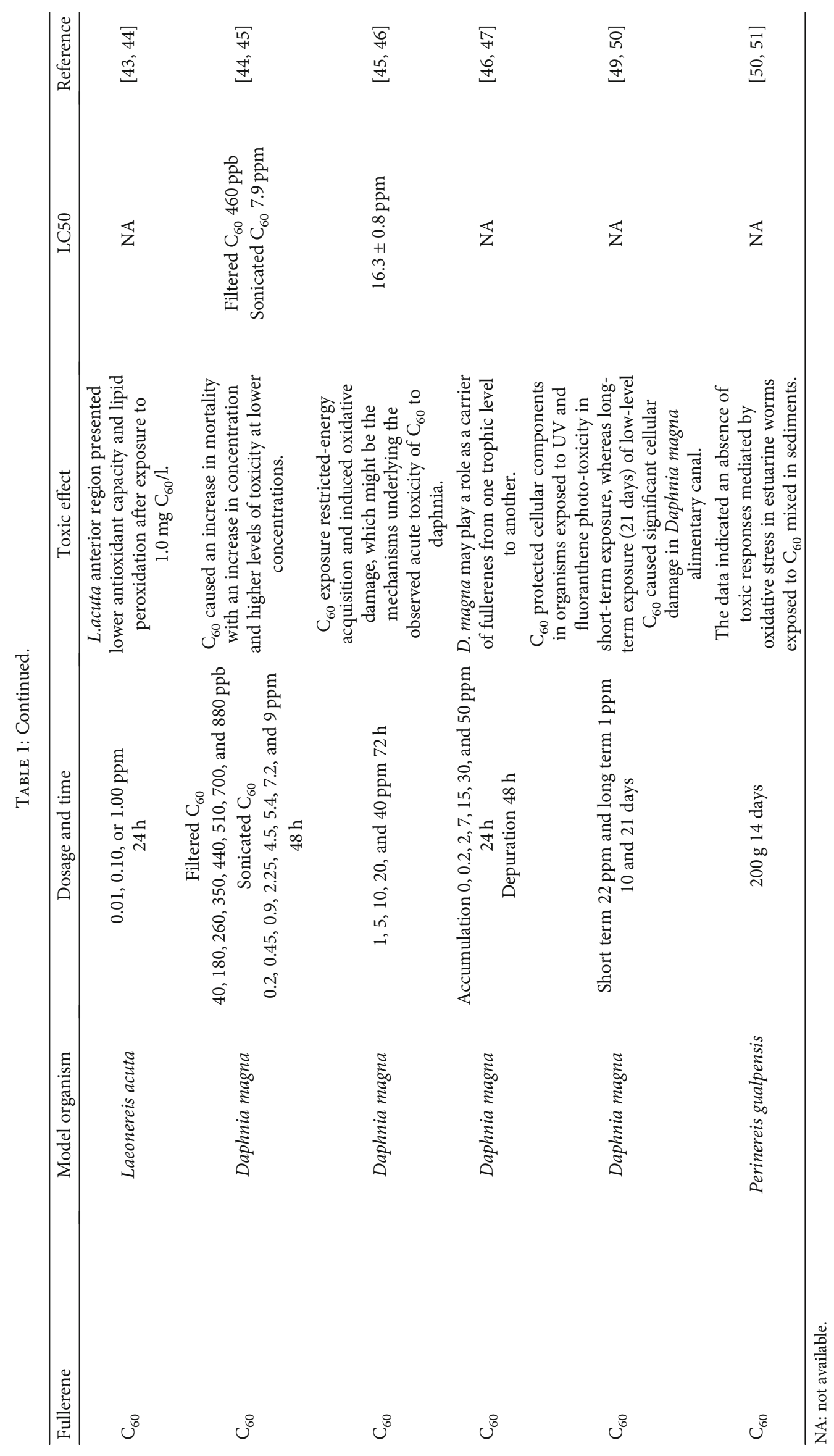


and larvae, reduced the hatching and survival rates, and caused pericardial edema, whereas $50 \mathrm{mg} / \mathrm{l}$ of fullerol hydroxylated $\mathrm{C}_{60}$ derivative did not affect the zebrafish embryos. The study also showed that the addition of an antioxidant (glutathione) mitigated the toxicity, suggesting the developmental toxicities are regulated by a free radical-induced mechanism or another form of oxidative stress. Furthermore, in the following study reported by Henry et al., $\mathrm{C}_{60}$ in two different forms $\left(\mathrm{C}_{60}\right.$-water) and tetrahydrofuran $\left(\mathrm{THF}-\mathrm{C}_{60}\right)$ were exposed to larval zebrafish to assess the changes in survival and gene expression [55]. The results demonstrated that the zebrafish larval survivability was compromised in THF$\mathrm{C}_{60}$ and THF-water. However, this phenomenon was not observed in the $\mathrm{C}_{60}$-water treatment group. In addition, in terms of gene expression, the biggest difference was displayed in the THF-C 60 group. The research indicated that toxic effects found in this study might be associated with the products of THF degradation rather than $\mathrm{C}_{60}$. Additionally, this also may explain the $\mathrm{C}_{60}$ toxicity found in other findings.

In another in vivo study conducted by Sarasamma et al. [56], waterborne $C_{60}$ was exposed to adult zebrafish for 12 days at 1 and 2 ppm concentrations, respectively, and fish's behavioral alterations were measured by phenomics approach. The results showed the alteration in fish's locomotor activity, response to a novel environment, aggression level, shoal formation, and color preference. Moreover, the fish also displayed dysregulation in the circadian rhythm locomotor activity. The corroboratory biochemical test results showed the induction of oxidative stress and DNA damage, followed by a significant reduction in antioxidative capacity and ATP level. The research group concluded low concentration of $\mathrm{C}_{60}$-induced multiple behavioral abnormalities in adult zebrafish. Similarly, in another prior study also conducted by Sarasamma et al. [57], the potential adverse effects of fullerene $\mathrm{C}_{70}$ exposure were assessed on adult zebrafish. Two different doses, $0.5 \mathrm{ppm}$ and $1.5 \mathrm{ppm}$, were exposed to adult zebrafish for two weeks. Similar to $C_{60}$ results, the results showed abnormalities in locomotion, explorative behavior, aggressiveness level, conspecific social interaction behavior, shoal formation, anxiety elevation, and circadian rhythm locomotor activity. Also, biochemical marker tests revealed a significant increase in superoxide dismutase (SOD), reactive oxygen species (ROS), cortisol, Hif 1- $\alpha$,

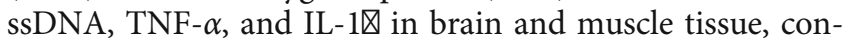
cluding several and similar toxic effects in altering the neurobehavior parameters of zebrafish after exposed to fullerenebased nanomaterials [57]. Taken together, the studies performed on Danio rerio in the embryos and adult stages indicate the importance of concentration range and exposure time in assessing the toxicity effect of fullerene over vertebrate model since different toxicological effects are observed in different studies under different concentrations and tests performed. To establish a concrete result of the toxicological effect of fullerene, it is necessary to accumulate more data on different parameters.

Next, in a previous study done by Oberdörster, when 0.5 ppm of uncoated $\mathrm{nC}_{60}$ was exposed to largemouth bass, Micropterus salmoides, for 48 hours, it resulted in significant lipid peroxidation in the brain [58]. In addition, GSH was observed to be marginally decreased in the fish's gills with an increase in water clarity. Further, in another experiment on Anabas testudineus, a freshwater fish, $\mathrm{C}_{60}$ was demonstrated to induce toxicity, specifically on reproductive parameters, after being exposed for 60 days at $5 \mathrm{mg} / \mathrm{l}$ and $10 \mathrm{mg} / \mathrm{l}$. The results showed a reduction in gonadal steroidogenesis with a decrease in steroidogenic enzymes, $3 \beta$ - and $17 \beta$ hydroxysteroid dehydrogenase. Furthermore, a significant decrement was also observed in the serum testosterone and estradiol in male and female fish, respectively, in concentration- and time-dependent manners. Thus, the study suggested stress induced by administration of $\mathrm{C}_{60}$ leads to reproductive toxicity in Anabas testudineus [59]. In a similar study protocol on Anabas testudineus, the toxic effect of $\mathrm{C}_{60}$ was evaluated on their behavior and hematology levels at 5 and $10 \mathrm{mg} / \mathrm{l}$ for $96 \mathrm{~h}$ and 60 days. The decline in acetylcholinesterase (AChE) enzyme activity in brain tissue showed prominent changes in fish behavior. Furthermore, the hematological parameter showed a significant reduction in blood cells with increased alanine and aspartate aminotransferase in serum. The results concluded that the sublethal concentration of $\mathrm{C}_{60}$ generates toxicity by affecting the normal physiology of $A$. testudineus, which might affect the ecosystem's health status $[59,60]$.

Forward, in another prior study by Sumi and Chitra and Blickley and McClellan-Green., the role of $\mathrm{C}_{60}$ was evaluated on the role of the brain antioxidant system of cichlid fish, Pseudetroplus maculatus $[60,61]$. In their study, $0.1 \mathrm{mg} / \mathrm{l}$ of $\mathrm{C}_{60}$ was administered to the fish for 96 hours. The results demonstrated no significant alterations in terms of the brain weight, whereas the notable reduction in antioxidant enzymes (like catalase, SOD, and GSH) and a significant increase in hydrogen peroxide and lipid peroxidation were found after $48 \mathrm{~h} \mathrm{C}_{60}$ treatment. Also, acetylcholinesterase (AChE), a marker enzyme for the brain, showed a significant reduction after exposure to $C_{60}$ at the end of 48-96 h. Thus, the work showed that the administration of $\mathrm{C}_{60}$ has adverse effects on the fish brain. The aqueous suspensions of $\mathrm{C}_{60}$ aggregates were studied on marine teleost Fundulus heteroclitus of an embryo, larvae, and adult stages. In natural seawater, the aggregates of $\mathrm{C}_{60}$ are mixed and precipitated in bottom water after 24 hours, resulting in very low mortality. No median lethal doses could be calculated at a concentration below $10 \mathrm{mg} / \mathrm{l}$. In addition, even though the $\mathrm{C}_{60}$ aggregates were attached to chorion, no effect in the development of the embryos on hatching success was observed. With higher exposure levels, the movement of $\mathrm{C}_{60}$ from chorion into the embryo tended to increase together with a dose-dependent increase in GSH and a decrease in lipid peroxidation (LPO) [61]. Further, the $\mathrm{C}_{60}$ exposed to Cyprinus carpio (common carp) demonstrated no effect on viability, whereas hampered growth occurred after $3 \mathrm{~h}$ of exposure to several concentrations of $\mathrm{C}_{60}$, which were $0.1,1$, and $10 \mathrm{mg} / \mathrm{l}$. Also, higher antioxidant competence to peroxyl radicals was observed in this fullerene than in other reactive colonies [62,63].

On the contrary, another study exposed three different chemical toxins, which were 6-hydroxydopamine, gentamicin, and cisplatinum, to a whole animal system in order to 
investigate the fullerenes' ability to protect the animal from the toxins. This model is useful to predict the toxicity and efficacy of this fullerene in mammals. When water-soluble fullerenes in both positive and negative charges were exposed to the zebrafish embryos at 1 and $500 \mu \mathrm{M}$ for $24-120 \mathrm{hpf}$, the results indicated that the fullerenes could give protection against the toxins, which can induce apoptotic cell death in a vertebrate. Furthermore, this work suggested that the relative potential for these compounds' pharmacologic use varies significantly with respect to stability $[63,64]$. Hence, more studies on different parameters of concentration, time, environmental factors, and vertebrate model are necessary to understand the toxic as well as beneficial properties of fullerene nanomaterials. We have compiled the results of different toxicity studies in Table 2.

\section{Biodistribution and Fate of Fullerene after Ingestion by Aquatic Organisms}

The biodistribution of fullerene on ingestion by aquatic organisms has been seldom addressed in the literature. Moreover, the concentration of fullerenes in many environmental matrices is still unknown, while quantification methods are under development $[33,65,66]$. However, NPs within cells may cause alterations in the cytoskeletal network $[67,68]$. Waissi-Leinonen and colleagues depicted the agglomeration of fullerene $\mathrm{C}_{60}$ in the gut area and damaged the microvilli of $C$. riparius [33]. Furthermore, in another study by Sforzini et al. and Barranger et al., $\mathrm{C}_{60}$ was reported to be distributed in mussel digestive gland cells $[36,37]$. In addition, the inhibition of mTOR might also be involved in pathophysiological perturbation induced by nanoparticle accumulation. Further, they stated that autophagic induction by fullerene $\mathrm{C}_{60}$ might reflect the degradation of unrecognized materials attempted by lysosomes. These materials might be identified by cells as damaged intracellular proteins and membranes or pathogens. The statement was made based on observations, where $\mathrm{C}_{60}$ accumulation in the lysosomal-vacuolar system of the epithelial cells is in the major digestive gland. Overall, the report suggested that dysregulation of mTOR 1 and 2 might inhibit the growth and reproduction of cells and organisms. Also, in a study, Pakarinen et al. and Oberdörster et al. reported that fullerene concentration in feces of $L$. variegatus was high in comparison to the bulk sediments $[39,40]$. The study suggested that high fullerene concentration in the form of pellets might partially stem from worm's consumption and absorption of some sediment fraction for nutritional purposes, whereas the fullerenes and other particles are excreted. Further, Tao et.al and Rouse et al. exposed D. magna to 0, $0.01,0.02,0.04,0.06$, and $1.0 \mathrm{mg} / \mathrm{l}$ for seven days and the results showed an increment in body burden of $\mathrm{C}_{60}$ along with a higher dose and bigger particle size $[69,70]$. Thus, the various papers and results suggest that more research is needed to understand the risks that fullerene may pose in sediments and organisms' bodies in different doses and concentrations under specific environmental conditions. Therefore, the limited information in the fullerene biodistribution is an important topic for future research.

\section{Discussion Based on Current Understanding}

The manufacturing of fullerenes to fit in for a specific task demands changes in their surface chemistries and properties. With the improvement according to demand, the fullerenes acquire novel physicochemical properties to be assessed for potential toxicological behavior compared to the natural ones. The impact of fullerenes via direct contact with water containing the amount of fullerene through skin and inhalation and via an indirect consumption of aquatic organisms exposure might pose a serious threat to human health in the long run $[65,67,71,72]$. Until now, the real effects associated with the interaction of fullerenes with the aquatic organisms are still lacking and remain challenging to analyze in the absence of relevant data.

The methods to evaluate the toxicity of fullerenes are evolving in recent years. The current understanding of the toxicity of fullerene must acknowledge that data compilation limitation serves as a barrier to understanding the interaction of fullerene inside the organism's body to interpret the results firmly. In reviewing the emerging environmental problem, it is highlighted that all significant effects on environmental fate, transport, and bioavailability of cocontaminants play a crucial part in understanding fullerene's toxicology.

The toxicity of fullerenes is, to date, poorly understood and contradictory in some cases. However, experimentation on fullerene toxicity testing has demonstrated that fullerene is toxic in some forms. Studies have shown that ROS and free radical production are among the main mechanisms of nanotoxicity; in turn, they might lead to inflammation, oxidative stress, and consequent damage to proteins, membranes, and DNA $[69,73]$. In a study, Oberdörster showed that fullerenes caused damage in fish brains [58]. Also, Fortner et al. and Howard demonstrated that fullerenes killed water fleas and showed bactericidal properties $[66,71]$. Furthermore, Sayes et al. and Daughton stated that toxicity is a sensitive function of surface derivatization $[68,72]$, while Rouse et al. and Nel et al. reported that the extent of aggregation, emulsion bases, and different solvents are important variables in the formation of aggregates [70, 73].

The studies discussed here with fullerene toxicity response on invertebrate and vertebrate models depicted contradictory results. Although fullerene $\mathrm{C}_{60}$ has been shown to cause mortality, ROS production, aggregation, and lipid peroxidation on a large basis, some studies have reported conflicting results. Waissi-Leinonen et al. demonstrated the effect of $\mathrm{C}_{60}$ in relative growth patterns of $C$. riparius in a bell-shaped dose-response manner [34]. Rajasree et al. and Marques et al. showed that exposure of sonicated $\mathrm{C}_{60}$ resulted in varied mortality in different stages of $A$. salina, whereas the filtered solution of $\mathrm{C}_{60}$ upon exposure revealed increasing mortality with an increase in concentration [42, 43]. Similarly, Blickley and McClellan-Green and Letts et al. also suggested the nontoxic effect of water-stirred suspensions of $\mathrm{C}_{60}$ at a concentration up to $10 \mathrm{mg} / \mathrm{l}$ in $\mathrm{H}$. heteroclitus at different life stages $[61,62]$.

Next, in another study, Tervonen et al. and Wang et al. mentioned the role of D. magna in carrying fullerene from one trophic level to another [46, 47]. Similarly, Pakarinen 


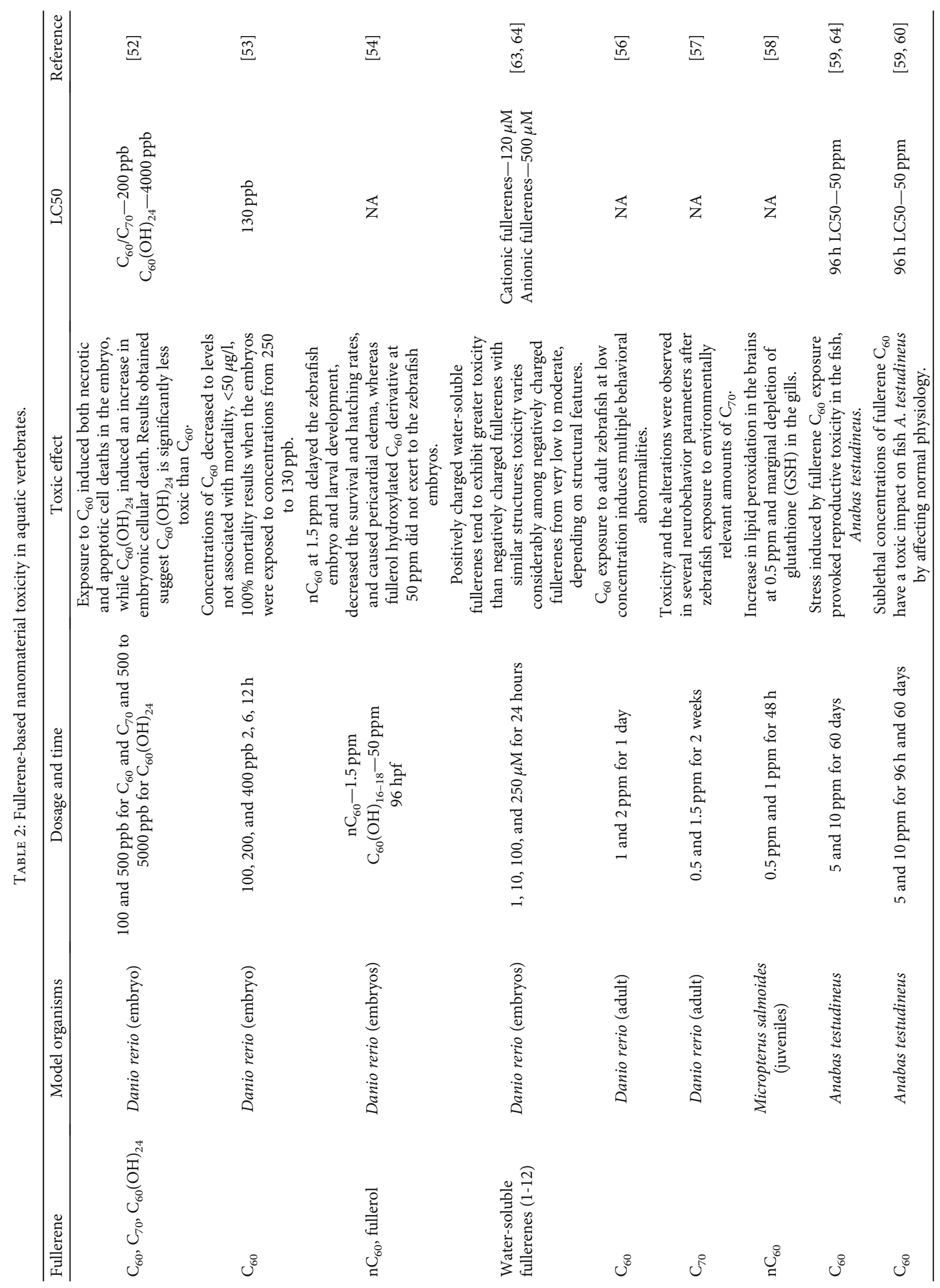




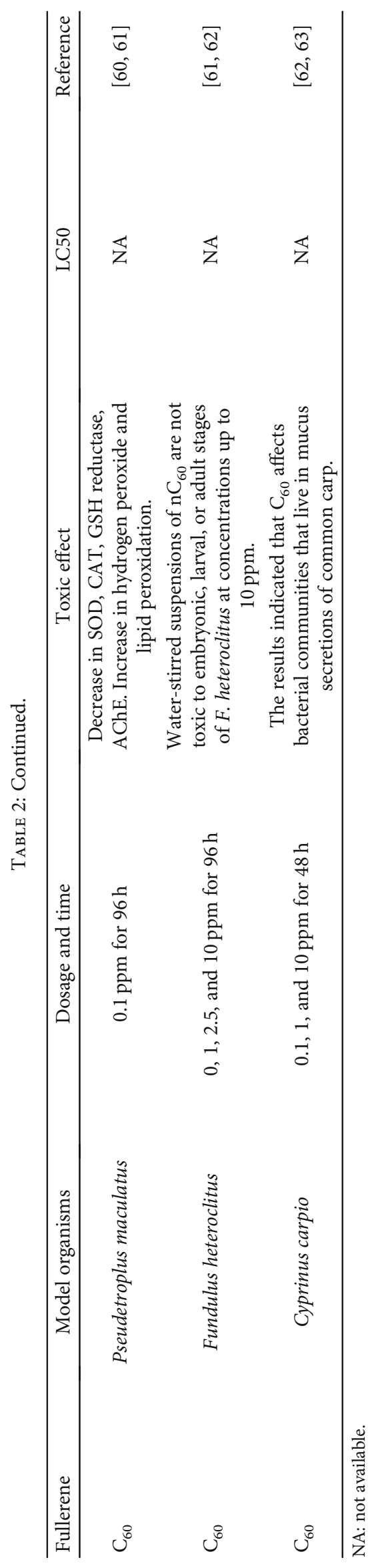


et al. and Oberdörster et al. demonstrated the fullerenes transfer process from sediment to sediment surface by L. variegatus through feeding and egestion $[39,40]$. This observation indicated that this transfer might potentially increase the fullerenes' bioavailability to epibenthic organisms, which might be more sensitive to the exposures and might further assist the transfer process in the food chain. Beuerle et al. and Sumi and Chitra stated that positively charged fullerene exhibited greater toxicity in the vertebrate model compared to negatively charged fullerene, which showed a dependency behavior on the structural features $[63,64]$.

\section{Conclusions of Future Directions}

Taken together, the toxicity of fullerenes to aquatic animals was clearly demonstrated. Since it has great medical implication potentials, it should be studied further in the future. We propose that techniques such as behavioral assay by phenomics, tissue distribution analysis by MASS spectrum, or isotope labeling for in vivo tracking should be used to study fullerene-induced toxicity in aquatic animals (i.e., specific biomarkers study, biodistribution, and interaction within an organism's body) to accumulate relevant data required to achieve a clear picture about fullerene-induced toxicity.

\section{Data Availability}

Data is available upon request to authors.

\section{Disclosure}

This paper has been submitted as a preprint in Research Square in the below link: https://www.preprints.org/ manuscript/202009.0376/v1.

\section{Conflicts of Interest}

The authors declare no conflicts of interest.

\section{Authors' Contributions}

N.M. and C.-D.H. are responsible for the conceptualization. T.-R.G., J-S.L., and C.-D.H. are responsible for the funding acquisition. T.-R.G., J-S.L., and C.-D.H. are responsible for the investigation. C.-D.H. is responsible for the project administration. A.L.C., G.A., P.S., J.M.S.R., and M.J.R. are responsible for the resources. T.-R.G. and C.-D.H. are responsible for the supervision. N.M. and C.-D.H. are responsible for the visualization. N.M., T.-R.G., J.-S.L., J.R.C., and C.-D.H are responsible for writing the original draft. All authors have read and agreed to the published version of the manuscript. Nemi Malhotra and Gilbert Audira are equal contribution authors.

\section{Acknowledgments}

This study was funded by the grants sponsored by the Ministry of Science and Technology (MOST107-2622-B-033-001-CC2, MOST108-2622-B-033-001-CC2, and MOST108-2313-B-
033-001-MY3 to C.-D.H., MOST109-2112-M153-002 to J.-S.L., and MOST108-2221-E033-017-MY3 to T.-R.G.).

\section{References}

[1] H. Kroto, J. R. Heath, S. C. O'Brien, R. F. Curl, and R. E. Smalley, " $\mathrm{C}_{60}$ : buckminsterfullerene," Nature, vol. 318, no. 6042 , pp. 162-163, 1985.

[2] P. Bhakta and B. Barthunia, "Fullerene and its applications: a review," Journal of Indian Academy of Oral Medicine and Radiology, vol. 32, no. 2, p. 159, 2020.

[3] R. Bakry, R. M. Vallant, M. Najam-ul-Haq et al., "Medicinal applications of fullerenes," International Journal of Nanomedicine, vol. 2, no. 4, pp. 639-649, 2007.

[4] S. Thakral and R. Mehta, "Fullerenes: an introduction and overview of their biological properties," Indian Journal of Pharmaceutical Sciences, vol. 68, no. 1, p. 13, 2006.

[5] V. Georgakilas, J. A. Perman, J. Tucek, and R. Zboril, "Broad family of carbon nanoallotropes: classification, chemistry, and applications of fullerenes, carbon dots, nanotubes, graphene, nanodiamonds, and combined superstructures," Chemical Reviews, vol. 115, no. 11, pp. 4744-4822, 2015.

[6] K. Aschberger, H. J. Johnston, V. Stone et al., "Review of fullerene toxicity and exposure - appraisal of a human health risk assessment, based on open literature," Regulatory Toxicology and Pharmacology, vol. 58, no. 3, pp. 455-473, 2010.

[7] P. J. Krusic, E. Wasserman, P. N. Keizer, J. R. Morton, and K. F. Preston, "Radical reactions of C60," Science, vol. 254, no. 5035, pp. 1183-1185, 1991.

[8] J. Tam, J. Liu, and Z. Yao, "Effect of microstructure on the antioxidant properties of fullerene polymer solutions," RSC Advances, vol. 3, no. 14, pp. 4622-4627, 2013.

[9] P. Prasanthi, G. S. Rao, and B. U. Gowd, "Mechanical behavior of fullerene reinforced fiber composites with interface defects through homogenization approach and finite element method," International Journal of Advanced Science and Technology, vol. 78, pp. 67-82, 2015.

[10] F. Giacalone and N. Martin, "Fullerene polymers: synthesis and properties," Chemical Reviews, vol. 106, no. 12, pp. 5136-5190, 2006.

[11] Y.-Y. Huang, S. K. Sharma, R. Yin, T. Agrawal, L. Y. Chiang, and M. R. Hamblin, "Functionalized fullerenes in photodynamic therapy," Journal of Biomedical Nanotechnology, vol. 10, no. 9, pp. 1918-1936, 2014.

[12] G. Lalwani and B. Sitharaman, "Multifunctional fullerene-and metallofullerene-based nanobiomaterials," Nano Life, vol. 3, no. 3, p. 1342003, 2013.

[13] H. Kazemzadeh and M. Mozafari, "Fullerene-based delivery systems," Drug Discovery Today, vol. 24, no. 3, pp. 898-905, 2019.

[14] P. R. Buseck, S. J. Tsipursky, and R. Hettich, "Fullerenes from the geological environment," Science, vol. 257, no. 5067, pp. 215-217, 1992.

[15] F. Mollaamin, T. T. Pham, D. M. T. Dang, M. Monajjemi, and C. M. Dang, "Modelling and Controlling of ion transport rate efficiency in Proton exchange membrane (PEMFC), alkaline (AFC), direct methanol (DMFC), phosphoric acid (PAFC), direct forming acid (DFAFC) and direct carbon (DCFC) fuel cells," Biointerface Research in Applied Chemistry, vol. 9, no. 4, pp. 4050-4059, 2019. 
[16] J. Cami, J. Bernard-Salas, E. Peeters, and S. E. Malek, "Detection of C60 and C70 in a young planetary nebula," Science, vol. 329, no. 5996, pp. 1180-1182, 2010.

[17] A. Nimibofa, E. A. Newton, A. Y. Cyprain, and W. Donbebe, "Fullerenes: synthesis and applications," Journal of Materials Science, vol. 7, pp. 22-33, 2018.

[18] R. Taylor, "Lecture Notes on Fullerene Chemistry," in A Handbook for Chemists, pp. 1-288, World Scientific, 1999.

[19] R. Haddon, L. Brus, and K. Raghavachari, "Rehybridization and $\pi$-orbital alignment: the key to the existence of spheroidal carbon clusters," Chemical Physics Letters, vol. 131, no. 3, pp. 165-169, 1986.

[20] I. Obodovskiy, "Radiation," in Fundamentals, applications, risks, and safety, Elsevier, 2019.

[21] S. Sweeney, D. Berhanu, S. K. Misra, A. J. Thorley, E. ValsamiJones, and T. D. Tetley, "Multi-walled carbon nanotube length as a critical determinant of bioreactivity with primary human pulmonary alveolar cells," Carbon, vol. 78, pp. 26-37, 2014.

[22] N. Anzar, R. Hasan, M. Tyagi, N. Yadav, and J. Narang, "Carbon nanotube - A review on Synthesis, Properties and plethora of applications in the field of biomedical science," Sensors International, vol. 1, 2020.

[23] A. S. Wu and T.-W. Chou, "Carbon nanotube fibers for advanced composites," Materials Today, vol. 15, no. 7-8, pp. 302-310, 2012.

[24] N. Saifuddin, A. Raziah, and A. Junizah, "Carbon nanotubes: a review on structure and their interaction with proteins," Journal of Chemistry, vol. 2013, Article ID 676815, 18 pages, 2013.

[25] Y. Kanbur and Z. Küçükyavuz, "Synthesis and characterization of surface modified fullerene," Fullerenes, Nanotubes, and Carbon Nanostructures, vol. 20, no. 2, pp. 119-126, 2012.

[26] R. Taylor and D. R. Walton, "The chemistry of fullerenes," Nature, vol. 363, no. 6431, pp. 685-693, 1993.

[27] K. N. Semenov, N. A. Charykov, V. A. Keskinov, A. K. Piartman, A. A. Blokhin, and A. A. Kopyrin, "Solubility of light fullerenes in organic solvents," Journal of Chemical \& Engineering Data, vol. 55, no. 1, pp. 13-36, 2010.

[28] L. Y. Chiang, R. B. Upasani, and J. W. Swirczewski, "Versatile nitronium chemistry for C60 fullerene functionalization," Journal of the American Chemical Society, vol. 114, no. 26, pp. 10154-10157, 1992.

[29] Z. Špitalský, L. Matějka, M. Šlouf et al., "Modification of carbon nanotubes and its effect on properties of carbon nanotube/epoxy nanocomposites," Polymer Composites, vol. 30, no. 10, pp. 1378-1387, 2009.

[30] V. N. Khabashesku and M. X. Pulikkathara, "Chemical modification of carbon nanotubes," Mendeleev Communications, vol. 16, no. 2, pp. 61-66, 2006.

[31] M. Maggini, G. Scorrano, and M. Prato, "Addition of azomethine ylides to C60: synthesis, characterization, and functionalization of fullerene pyrrolidines," Journal of the American Chemical Society, vol. 115, no. 21, pp. 9798-9799, 1993.

[32] L. Lagadic and T. Caquet, "Invertebrates in testing of environmental chemicals: are they alternatives?," Environmental Health Perspectives, vol. 106, suppl 2, pp. 593-611, 1998.

[33] G. C. Waissi-Leinonen, E. J. Petersen, K. Pakarinen, J. Akkanen, M. T. Leppänen, and J. V. K. Kukkonen, “Toxicity of fullerene (C60) to sediment-dwelling invertebrate Chironomus riparius larvae," Environmental Toxicology and Chemistry, vol. 31, no. 9, pp. 2108-2116, 2012.
[34] G. C. Waissi-Leinonen, I. Nybom, K. Pakarinen, J. Akkanen, M. T. Leppänen, and J. V. K. Kukkonen, "Fullerenes $\left(\mathrm{nC}_{60}\right)$ affect the growth and development of the sediment-dwelling invertebrate Chironomus riparius larvae," Environmental Pollution, vol. 206, pp. 17-23, 2015.

[35] L. Canesi, C. Ciacci, D. Vallotto, G. Gallo, A. Marcomini, and G. Pojana, "In vitro effects of suspensions of selected nanoparticles (C60 fullerene, $\mathrm{TiO}_{2}, \mathrm{SiO}_{2}$ ) on Mytilus hemocytes," Aquatic Toxicology, vol. 96, no. 2, pp. 151-158, 2010.

[36] S. Sforzini, C. Oliveri, A. Barranger et al., "Effects of fullerene C60 in blue mussels: role of mTOR in autophagy related cellular/tissue alterations," Chemosphere, vol. 246, p. 125707, 2020.

[37] A. Barranger, L. M. Langan, V. Sharma et al., "Antagonistic interactions between benzo [a] pyrene and fullerene (C60) in toxicological response of marine mussels," Nanomaterials, vol. 9, no. 7, p. 987, 2019.

[38] S. Ponte, E. A. Moore, C. T. Border, C. W. Babbitt, and A. C. Tyler, "Fullerene toxicity in the benthos with implications for freshwater ecosystem services," Science of the Total Environment, vol. 687, pp. 451-459, 2019.

[39] K. Pakarinen, E. J. Petersen, M. T. Leppänen, J. Akkanen, and J. V. K. Kukkonen, "Adverse effects of fullerenes $\left(\mathrm{nC}_{60}\right)$ spiked to sediments on Lumbriculus variegatus (Oligochaeta)," Environmental Pollution, vol. 159, no. 12, pp. 3750-3756, 2011.

[40] E. Oberdörster, S. Zhu, T. M. Blickley, P. McClellan-Green, and M. L. Haasch, "Ecotoxicology of carbon-based engineered nanoparticles: effects of fullerene $\left(\mathrm{C}_{60}\right)$ on aquatic organisms," Carbon, vol. 44, no. 6, pp. 1112-1120, 2006.

[41] K. H. Ji, J. K. Kim, and K. H. Choi, "Sunlight enhances toxicity of fullerene (C60) to freshwater invertebrates Daphnia magna and Moina macrocopa," Journal of Health Sciences, vol. 51, no. 1, pp. 35-45, 2014.

[42] S. R. R. Rajasree, V. G. Kumar, L. S. Abraham, and N. Manoharan, "Assessment on the toxicity of engineered nanoparticles on the lifestages of marine aquatic invertebrate Artemia salina," International Journal of Nanoscience, vol. 10, pp. 1153-1159, 2011.

[43] B. F. Marques, L. F. Cordeiro, L. W. Kist et al., "Toxicological effects induced by the nanomaterials fullerene and nanosilver in the polychaeta Laeonereis acuta (Nereididae) and in the bacteria communities living at their surface," Marine Environmental Research, vol. 89, pp. 53-62, 2013.

[44] S. B. Lovern and R. Klaper, "Daphnia magna mortality when exposed to titanium dioxide and fullerene (C60) nanoparticles," Environmental Toxicology and Chemistry, vol. 25, no. 4, pp. 1132-1137, 2006.

[45] X. Lv, B. Huang, X. Zhu et al., "Mechanisms underlying the acute toxicity of fullerene to Daphnia magna: energy acquisition restriction and oxidative stress," Water Research, vol. 123, pp. 696-703, 2017.

[46] K. Tervonen, G. Waissi, E. J. Petersen, J. Akkanen, and J. V. Kukkonen, "Analysis of fullerene-C60 and kinetic measurements for its accumulation and depuration in Daphnia magna," Environmental Toxicology and Chemistry, vol. 29, no. 5, pp. 1072-1078, 2010.

[47] P. Wang, B. Huang, Z. Chen et al., "Behavioural and chronic toxicity of fullerene to Daphnia magna: mechanisms revealed by transcriptomic analysis," Environmental Pollution, vol. 255, p. 113181, 2019.

[48] E. A. Moore, C. W. Babbitt, S. J. Connelly, A. C. Tyler, and G. Rogalskyj, "Cascading ecological impacts of fullerenes in 
freshwater ecosystems," Environmental Toxicology and Chemistry, vol. 38, no. 8, pp. 1714-1723, 2019.

[49] X. Yang, R. Edelmann, and J. Oris, "Suspended $C_{60}$ nanoparticles protect against short-term UV and fluoranthene photoinduced toxicity, but cause long-term cellular damage in Daphnia magna," Aquatic Toxicology, vol. 100, no. 2, pp. 202-210, 2010.

[50] M. Díaz-Jaramillo, J. Ribas, A. M. da Rocha et al., "Antioxidant responses in the polychaetePerinereis gualpensis(Nereididae) exposed to the carbon nanomaterial fullerene (C60)," Chemistry and Ecology, vol. 27, no. 1, pp. 43-48, 2011.

[51] S. N. al-Subiai, V. M. Arlt, P. E. Frickers et al., "Merging nanogenotoxicology with eco-genotoxicology: An integrated approach to determine interactive genotoxic and sub-lethal toxic effects of $\mathrm{C}_{60}$ fullerenes and fluoranthene in marine mussels, Mytilus sp.," Mutation Research/Genetic Toxicology and Environmental Mutagenesis, vol. 745, no. 1-2, pp. 92-103, 2012.

[52] C. Y. Usenko, S. L. Harper, and R. L. Tanguay, "In vivo evaluation of carbon fullerene toxicity using embryonic zebrafish," Carbon, vol. 45, no. 9, pp. 1891-1898, 2007.

[53] T. B. Henry, E. J. Petersen, and R. N. Compton, “Aqueous fullerene aggregates $\left(\mathrm{nC}_{60}\right)$ generate minimal reactive oxygen species and are of low toxicity in fish: a revision of previous reports," Current Opinion in Biotechnology, vol. 22, no. 4, pp. 533-537, 2011.

[54] X. Zhu, L. Zhu, Y. Li, Z. Duan, W. Chen, and P. J. J. Alvarez, "Developmental toxicity in zebrafish (Danio rerio) embryos after exposure to manufactured nanomaterials: buckminsterfullerene aggregates (nC60) and fullerol," Environmental Toxicology and Chemistry, vol. 26, no. 5, pp. 976-979, 2007.

[55] T. B. Henry, F. M. Menn, J. T. Fleming, J. Wilgus, R. N. Compton, and G. S. Sayler, "Attributing effects of aqueous C60 nanoaggregates to tetrahydrofuran decomposition products in larval zebrafish by assessment of gene expression," Environmental Health Perspectives, vol. 115, no. 7, pp. 1059-1065, 2007.

[56] S. Sarasamma, G. Audira, S. Juniardi et al., "Evaluation of the effects of carbon 60 nanoparticle exposure to adult zebrafish: a behavioral and biochemical approach to elucidate the mechanism of toxicity," International Journal of Molecular Sciences, vol. 19, no. 12, p. 3853, 2018.

[57] S. Sarasamma, G. Audira, P. Samikannu et al., "Behavioral impairments and oxidative stress in the brain, muscle, and gill caused by chronic exposure of C70 nanoparticles on adult zebrafish," International Journal of Molecular Sciences, vol. 20, no. 22 , p. $5795,2019$.

[58] E. Oberdörster, "Manufactured nanomaterials (fullerenes, C60) induce oxidative stress in the brain of juvenile largemouth bass," Environmental Health Perspectives, vol. 112, no. 10, pp. 1058-1062, 2004.

[59] N. Sumi and K. Chitra, "Impact of fullerene C 60 on behavioral and hematological changes in the freshwater fish, Anabas testudineus (Bloch, 1792)," Applied Nanoscience, vol. 9, no. 8, pp. 2147-2167, 2019.

[60] N. Sumi and K. Chitra, "Fullerene (C60) induced alteration in the brain antioxidant system of the cichlid fish, Pseudetroplus maculatus (Bloch, 1795)," Journal of Global Biosciences, vol. 6, no. 4, pp. 4908-4917, 2017.

[61] T. M. Blickley and P. McClellan-Green, "Toxicity of aqueous fullerene in adult and larval Fundulus heteroclitus," Environmental Toxicology and Chemisty, vol. 27, no. 9, pp. 19641971, 2008.
[62] R. E. Letts, T. C. B. Pereira, M. R. Bogo, and J. M. Monserrat, "Biologic responses of bacteria communities living at the mucus secretion of common carp (Cyprinus carpio) after exposure to the carbon nanomaterial fullerene (C 60)," Archives of Environmental Contamination and Toxicology, vol. 61, no. 2, pp. 311-317, 2011.

[63] F. Beuerle, P. Witte, U. Hartnagel, R. Lebovitz, C. Parng, and A. Hirsch, "Cytoprotective activities of water-soluble fullerenes in zebrafish models," Journal of Experimental Nanoscience, vol. 2, no. 3, pp. 147-170, 2007.

[64] N. Sumi and K. C. Chitra, "Possible role of C 60 fullerene in the induction of reproductive toxicity in the freshwater fish, Anabas testudineus (Bloch, 1792)," Environmental Science and Pollution Research, vol. 27, no. 16, pp. 19603-19615, 2020.

[65] C. W. Isaacson, M. Kleber, and J. A. Field, “Quantitative analysis of fullerene nanomaterials in environmental systems: a critical review," Environmental Science \& Technology, vol. 43, no. 17, pp. 6463-6474, 2009.

[66] J. Fortner, D. Y. Lyon, C. M. Sayes et al., "C60 in water: nanocrystal formation and microbial response," Environmental Science \& Technology, vol. 39, no. 11, pp. 4307-4316, 2005.

[67] O. Ispanixtlahuatl-Meráz, R. P. Schins, and Y. I. Chirino, "Cell type specific cytoskeleton disruption induced by engineered nanoparticles," Environmental Science: Nano, vol. 5, no. 2, pp. 228-245, 2018.

[68] C. M. Sayes, J. D. Fortner, W. Guo et al., "The differential cytotoxicity of water-soluble fullerenes," Nano Letters, vol. 4, no. 10, pp. 1881-1887, 2004.

[69] X. Tao, Y. He, B. Zhang, Y. Chen, and J. B. Hughes, "Effects of stable aqueous fullerene nanocrystal $\left(\mathrm{nC}_{60}\right)$ on Daphnia magna: evaluation of hop frequency and accumulations under different conditions," Journal of Environmental Sciences, vol. 23, no. 2, pp. 322-329, 2011.

[70] J. G. Rouse, J. Yang, A. R. Barron, and N. A. Monteiro-Riviere, "Fullerene-based amino acid nanoparticle interactions with human epidermal keratinocytes," Toxicology In Vitro, vol. 20, no. 8, pp. 1313-1320, 2006.

[71] C. Howard, "Small particles-big problems," International Laboratory News, vol. 34, no. 2, pp. 28-29, 2004.

[72] C. G. Daughton, "Non-regulated water contaminants: emerging research," Environmental Impact Assessment Review, vol. 24, no. 7-8, pp. 711-732, 2004.

[73] A. Nel, T. Xia, L. Mädler, and N. Li, "Toxic potential of materials at the nanolevel," Science, vol. 311, no. 5761, pp. 622-627, 2006. 